\title{
Renal insufficiency in Ghanaian HIV infected patients: need for dose adjustment
}

\author{
${ }^{*}$ Owiredu WKBA${ }^{1}$, Quaye L1 ${ }^{1}$, Amidu $\mathrm{N}^{2}$, Addai-Mensah $\mathrm{O}^{2}$ \\ 1. Department of Molecular Medicine, School of Medical Sciences, College of Health Sciences, Kwame Nkrumah University \\ of Science and Technology, Kumasi, Ghana \\ 2. Department of Medical Laboratory Technology, Faculty of Allied Health Sciences, College of Health Sciences, Kwame \\ Nkrumah University of Science and Technology, Kumasi, Ghana
}

\begin{abstract}
Background: Antiretrovirals (ARVs) could lead to clinically significant nephrotoxicity and as such will require dose adjustments in the presence of renal insufficiency.

Objective: To explore renal function estimating equations as alternatives for glomerular filtration rate (GFR) measurement in a stable cohort of HIV-infected patients.

Method: In estimating renal insufficiency in Ghanaian HIV-infected patients, GFR for 276 HAART-naïve patients and 166 patients on HAART was estimated with the Cockcroft-Gault, 4v-MDRD and CKD-EPI estimating equations.

Results: Females outnumbered males by 3 to 1 in the HAART-naïve group and 4 to 1 in subjects on HAART. The prevalence of renal insufficiency calculated with the Cockcroft-Gault, 4v-MDRD and CKD-EPI equations was 8.7\%, 9.1\% and $8.7 \%$ in HAART-naïve patients; $14.5 \%, 12.6 \%$ and $12.6 \%$ in patients on HAART; $7.7 \%, 11.5 \%$ and $11.5 \%$ in HAARTnaïve males; $10.8 \%, 8.1 \%$ and $8.1 \%$ in males on HAART; $9.1 \%, 8.0 \%$ and $7.5 \%$ in HAART-naïve females and $15.5 \%, 14.0 \%$ and $14.0 \%$ in females on HAART. The CKD-EPI equation yielded lower bias when compared to the Cockcroft-Gault and $4 \mathrm{v}-\mathrm{MDRD}$ equations.

Conclusion: Renal insufficiency is not uncommon among HIV infected Ghanaian patients. A significant proportion (10 to $11 \%$ ) will require ARV dose adjustment at the time of initiating therapy or sometime during on-going therapy.

Keywords: Antiretroviral, predictive equation, renal function, HIV, Ghana

African Health Sciences 2013; (1): 101 - 111 http://dx.doi.org/10.4314/ahs.v13i1.14
\end{abstract}

\section{Introduction}

Chronic kidney disease (CKD) is essentially compromised kidney function that persists for more than three (3) months ${ }^{1}$. Chronic kidney disease is becoming a public health problem with recently published reports emphasizing it as being underdiagnosed and under-treated ${ }^{2,3}$. Recognition of this chronic condition is therefore crucial to facilitate the employment of measures that can slow progression to end-stage renal disease (ESRD).

Abnormal renal function has been identified in about $30 \%$ of human immunodeficiency virus (HIV) infected patients ${ }^{4}$ and a more recent analysis of a large urban United States (US) HIV clinic showed that approximately $15.5 \%$ of the patients

* Corresponding author:
William K.B.A. Owiredu
Department of Molecular Medicine
Kwame Nkrumah University of Science and
Technology
Kumasi, Ghana
Tel: +233-244 228667
E-mail: wkbaowiredu@yahoo.com

African Health Sciences Vol 13 Issue 1 March 2013 had chronic or end-stage renal disease ${ }^{5}$. Individuals of African descent have been impacted most by renal disease as a complication of HIV infection with HIV-associated nephropathy (HIVAN) being the most commonly detected abnormality ${ }^{6,7}$. Human immunodeficiency virus associated nephropathy has been documented in sub-Saharan Africa ${ }^{8,9}$ but little is known about its prevalence or impact.

Antiretroviral (ARV) drug combination regimen has been proven to prolong life and reduce HIV-related morbidity and mortality ${ }^{10}$ and discontinuation of ARV has been shown to increase mortality not just from HIV but also from other causes. Against the background that some antiretroviral therapies have been identified to have clinically significant nephrotoxicity, anticipation and management of the complications of long-term antiretroviral therapy (drug induced kidney damage) and long-standing HIV infection (HIVAN) are becoming increasingly important.

Current guidelines for the management of HIV-infected patients include initial assessment to rule out kidney disease and to identify patients at risk for 
developing kidney disease ${ }^{11}$. Glomerular filtration rate (GFR) compared to serum creatinine or 24hour urine creatinine measurement is considered the best overall index of kidney function in health and disease because of the attendant problems associated with creatinine measurement and 24-hour urine creatinine clearance estimation ${ }^{12,13}$. Kidney function can be reliably estimated by calculating creatinine clearance $(\mathrm{CrCl})$ or $\mathrm{GFR}$ through use of the Cockcroft-Gault or Modification of Diet in Renal Disease (MDRD) equations respectively ${ }^{14,15}$. A GFR $<60 \mathrm{~mL} / \mathrm{min} / 1.73 \mathrm{~m}^{2}$ meets the criteria for renal insufficiency and this cut-off is supported by epidemiological data linking lower GFR to an increased frequency of hospitalization, cardiovascular events or death. Neither of the equations has been specifically validated in the HIV-infected population but they remain the most highly validated formulas available and both equations are more sensitive than measurement of serum creatinine alone ${ }^{16}$.

With the formulation of the chronic kidney disease epidemiology collaboration (CKD-EPI) equation which has been found to be more accurate than the MDRD equation, this paper seeks to find the proportion of Ghanaian HIV-infected patients (HAART naïve and on HAART) with renal insufficiency by using the three renal function equations to assess which of the equations best defines renal insufficiency in the study population and also to determine the proportion of the study population who would require ART dose adjustments.

\section{Methods}

\section{Study setting}

This cross-sectional study was carried out at the antiretroviral (ART) clinic in the Regional Hospital, Bolgatanga which is located in the Upper East Region of Ghana from September 2008 to September 2009. The Upper East Region is located in the north-eastern corner of Ghana and covers an area of about $1,463 \mathrm{~km}^{2}$ (564.9 sq mi) with a current catchment area population projected to be 1,004,244. The Upper East Region shares borders with Togo on the East and Burkina Faso on the West. The capital, Bolgatanga is cosmopolitan in nature with inhabitants not only hailing from the northern region but also from other parts of Ghana and the sub-region. The climate is tropical with a rainy season from May to October and a long dry season with virtually no rainfall from October to April. Temperatures range between a maximum of $45^{\circ} \mathrm{C}$ in March/April and at least $12^{\circ} \mathrm{C}$ in December.

\section{Study population}

Four hundred and forty-two people living with HIV / AIDS (PLWHA) visiting the ART clinic at the Regional Hospital, Bolgatanga were recruited for this study. This comprised of two hundred and seventysix highly active antiretroviral therapy (HAART)-naïve patients and one hundred and sixty-six patients on HAART.

\section{Inclusion criteria}

Patients with age ranging between 20 to 60 years, confirmed to be positive for HIV 1, 2 or both and have undergone adherence counselling at the ART clinic were included in the study.

\section{Exclusion criteria}

Patients who were hypertensive, diabetic, pregnant and had recorded history of renal disease were excluded from the study.

Written informed consent was obtained from all the patients included in the study and ethical clearance was obtained from the Clinical and Research Development Board of the hospital.

\section{Sample collection and preparation}

$5 \mathrm{ml}$ of venous blood was taken from each patient. $3 \mathrm{ml}$ was dispensed into vacutainer plain tube and allowed to clot. The clotted sample was then centrifuged at $1500 \mathrm{rpm}$ for 10 minutes at room temperature to obtain serum which were kept frozen at $-20^{\circ} \mathrm{C}$ until analyzed. The remaining $2 \mathrm{ml}$ of the venous blood sample was dispensed into vacutainer ethylene diamine tetraacetic acid (EDTA) tubes and was used for CD4 and CD3 estimation.

\section{Study procedures \\ Weight}

Weight to the nearest $0.1 \mathrm{~kg}$ in light clothing was determined at the time of recruitment with a bathroom scale (Zhongshan Camry Electronics Co. Ltd. Guangdong, China).

\section{CD4 and CD3 Lymphocytes}

Absolute cell counts of CD4 and CD3 Tlymphocytes in non-haemolyzed whole blood were assayed using the BD FACSCOUNT system (Becton Dickenson and Company, California, USA) which uses fluorescent light to provide the information necessary for the instrument to count cells. 


\section{Biochemical assays \\ Urea}

The method for this assay is based on a modification of the Urease/Glutamate dehydrogenase (GLDH) method by ${ }^{17}$ where urea is hydrolyzed to ammonia $\left(\mathrm{NH}_{3}\right)$ and carbon dioxide $\left(\mathrm{CO}_{2}\right)$ in the presence of water and urease. Liberated ammonia reacts with áketoglutarate in the presence of NADH and GLDH to form L-Glutamate and $\mathrm{NAD}^{+}$. As the reaction proceeds, the absorbance at $340 \mathrm{~nm}$ decreases and the initial rate of this change is proportional to the amount of urea in the sample.

\section{Creatinine}

This assay is based on the Jaffe (modified kinetic) method described by ${ }^{18}$. Creatinine reacts with picric acid in alkaline conditions to form a colour complex which absorbs at $510 \mathrm{~nm}$. The rate of formation of colour is proportional to the creatinine in the sample.

\section{Albumin}

This assay is based on the method of [19] where at a controlled $\mathrm{pH}$, bromocresol green (BCG) forms a coloured complex with albumin. The intensity of the colour at $630 \mathrm{~nm}$ is directly proportional to the albumin content.

All biochemical assays were determined using ATAC 8000 Random Chemistry Analyzer according to the reagent manufacturer's instruction - JAS ${ }^{\mathrm{TM}}$ diagnostics, Inc. (JAS Diagnostics, Inc. Miami Florida, USA). HAART usage is defined as receipt of two nucleoside reverse transcriptase inhibitors (NRTI) and one non-nucleoside reverse transcriptase inhibitor (NNRTI) or one protease inhibitor (PI).

\section{Measurement of renal function}

The Infectious Diseases Society of America (IDSA) renal guidelines state that for CKD staging purposes, the simplified MDRD equation is preferred but for dosage modification, the Cockcroft-Gault would be appropriate as studies of medications in renal failure have traditionally used the Cockcroft-Gault equation 11. Currently, the only validated renal function equation in Ghana is among CKD patients where Cockcroft-Gault and four-variable Modification of Diet in Renal Disease (4v-MDRD) equations were recommended out of the six equations validated ${ }^{20}$. This study assessed renal function in HIV patients using three renal function equations, namely the Cockcroft-Gault equation for estimating $\mathrm{CrCl}, 4 \mathrm{v}$ -
MDRD and the Chronic Kidney Disease Epidemiology Collaboration (CKD-EPI). None of these renal function estimating equations have been validated against accepted gold standards among Ghanaian HIV infected patients.

\section{Gold standards}

Clearance of inulin, iothalamate and other radioisotopes as measurements for GFR are not readily available and too expensive to be used for screening. Creatinine clearance therefore remains the most widely used, widely available and sufficiently accurate method for measuring GFR but the required 24-hour urine collection is too cumbersome and potentially beset by pitfalls. Unfortunately, none of the estimating equations used in this study were compared to a gold standard.

\section{Estimating equations and Staging of kidney function}

Estimated GFR's (eGFR) were used to stratify the study population into five stages based on the staging system of the Kidney Disease Outcomes Quality Initiative (K/DOQI) for renal disease classification ${ }^{12}$ where: Stage 1 (Kidney damage with normal or increased GFR) $=$ GFR $>90 \mathrm{~mL} / \mathrm{min} / 1.73 \mathrm{~m}^{2}$; Stage 2 (Kidney damage with mildly decreased GFR) $=60-89 \mathrm{~mL} / \mathrm{min} / 1.73 \mathrm{~m}^{2}$; Stage 3 (Moderately decreased GFR) $=30-59 \mathrm{~mL} / \mathrm{min} / 1.73 \mathrm{~m}^{2}$; Stage 4 (Severely decreased GFR) $=15-29 \mathrm{~mL} / \mathrm{min} /$ $1.73 \mathrm{~m}^{2}$ and Stage 5 (Kidney failure) $=<15 \mathrm{~mL} /$ $\min / 1.73 \mathrm{~m}^{2}$.

\section{Renal function estimating equations}

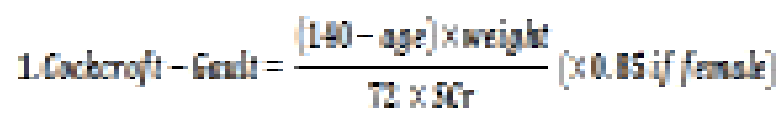

2-5T-1002

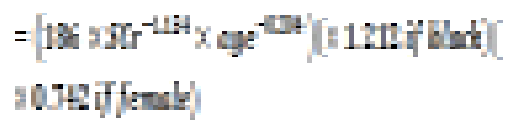

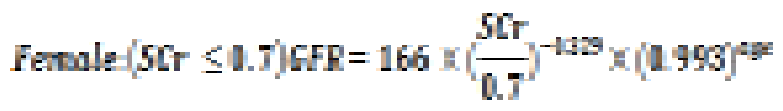

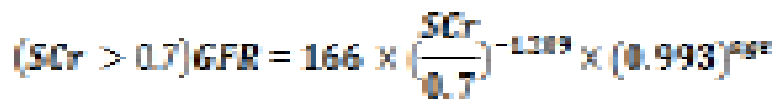

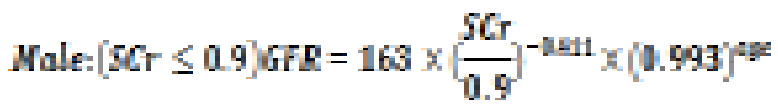

$$
\text { (SCT }>0.97 G F R=163 \times\left(\frac{5 \mathrm{~T}}{\mathrm{~T}}\right)^{-\mathrm{L}}
$$


Units of measurement: Age (years); creatinine $(\mathrm{mg} / \mathrm{dL})$; weight $(\mathrm{kg})$; GFR $\left(\mathrm{mL} / \mathrm{min} / 1.73 \mathrm{~m}^{2}\right)$

\section{Statistical analysis}

Results are expressed as Means \pm SEM. Unpaired ttest was used to compare the means and a $\mathrm{p}$-value $<0.05$ was considered to be statistically significant. Linear regression analysis between the renal function estimating equations and age, weight, $\mathrm{CD} 4$, creatinine and albumin were performed to assess their ability to predict GFR. Bland-Altman test statistic was used to compare the levels of performance of the three estimating equations. GraphPad Prism versions 5.00 (www.graphpad.com) and MedCalc ${ }^{\circledR}$ version 10.2.0.0 (www.medcalc.be) for windows were used for statistical analysis.

\section{Results}

\section{General characteristics}

Out of the 276 HAART-naïve subjects, 78 (28.3\%) were males and $198(71.7 \%)$ were females giving a male to female ratio of $1: 3$. The male to female ratio for patients on HAART was 1:4 representing a proportion of $22.3 \%(37 / 166)$ and $77.7 \%$ (129/ 166) respectively. Analysis of the general characteristics from table 1 , shows patients on
HAART and females on HAART being older $(\mathrm{p}<$ $0.001)$ and heavier $(\mathrm{p}<0.05 ; \mathrm{p}<0.001)$ respectively, than their HAART-naïve counterparts. Males on HAART were also heavier $(\mathrm{p}<0.001)$ compared to their HAART-naïve counterparts but a comparison of age showed no significant difference. The mean CD 4 cell counts in patients on HAART was significantly higher $(\mathrm{p}<0.05)$ compared to their HAART-naïve counterparts but no significant difference was observed in the mean CD4 values of naïve males and females compared to their counterparts on HAART (table 1). The mean concentration of the measured analytes BUN, creatinine and albumin when compared in all the study populations showed no statistical significant difference. Patients on HAART were further stratified by specific drugs of the combination therapy which mostly comprised of two nucleoside reverse transcriptase inhibitors (NRTI's) and one nonnucleoside reverse transcriptase inhibitor (NNRTI). $41.6 \%(69 / 166)$ were on a combination therapy of Combivir + Efavirenz; 41.0\% (68/166) on Combivir + Nevirapine; $10.8 \%(18 / 166)$ on Stavudine + Lamivudine + Nevirapine and $6.6 \%(11 / 166)$ on Stavudine + Lamivudine + Efavirenz (table 1). Combivir is a combined drug of Zidovudine (AZT) and Lamivudine (3TC).

Table 1: General characteristics of the study population

\begin{tabular}{|c|c|c|c|c|c|c|}
\hline \multirow[t]{2}{*}{ Parameters } & \multicolumn{2}{|c|}{ HIV patients } & \multicolumn{2}{|c|}{ Male patients } & \multicolumn{2}{|c|}{ Female patients } \\
\hline & HAART- & On HAART & HAART- & On HAART & HAART- & On HAART \\
\hline Age (yrs) & $33.42 \pm 0.88$ & $36.91 \pm 0.77 * *$ & $36.68 \pm 2.15$ & $39.63 \pm 1.68$ & $32.17 \pm 0.89 \ddagger$ & $36.10 \pm 0.85 \S \S$ \\
\hline WT (kg) & $48.93 \pm 1.24$ & $54.92 \pm 3.61 *$ & $54.08 \pm 2.44$ & $75.50 \pm 2.50 \dagger \dagger$ & $47.00 \pm 1.34 \ddagger \ddagger$ & $51.18 \pm 3.04 \# \#$ \\
\hline CD4 $\left(\right.$ cell mm $\left.{ }^{-3}\right)$ & $272.60 \pm 13.24$ & $315.30 \pm 13.92^{*}$ & $251.60 \pm 26.40$ & $277.70 \pm 29.85$ & $295.50 \pm 17.33$ & $326.30 \pm 15.78$ \\
\hline CD3 $\left(\right.$ cell mm$\left.m^{-3}\right)$ & $1243.00 \pm 39.27$ & $71216.00 \pm 45.19$ & $1251.00 \pm 89.3$ & $331148.00 \pm 92.36$ & $61276.00 \pm 56.32$ & $1238.00 \pm 52.08$ \\
\hline \multicolumn{7}{|l|}{ Analytes } \\
\hline Urea $\left(\mathrm{mmol} \mathrm{L}^{-1}\right)$ & $5.17 \pm 0.25$ & $4.76 \pm 0.35$ & $5.19 \pm 0.43$ & $5.88 \pm 1.44$ & $5.13 \pm 0.31$ & $4.42 \pm 0.14$ \\
\hline Creatinine $\left(\mu \mathrm{mol} \mathrm{L}{ }^{-1}\right)$ & 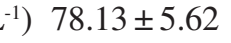 & $72.72 \pm 2.77$ & $91.41 \pm 14.97$ & $82.35 \pm 6.17$ & $70.33 \pm 5.14$ & $69.76 \pm 3.06$ \\
\hline Albumin $\left(\mathrm{g} \mathrm{L}^{-1}\right)$ & $36.58 \pm 2.54$ & $4 \quad 38.36 \pm 0.54$ & $33.58 \pm 1.27$ & $36.35 \pm 1.26$ & $37.99 \pm 3.48$ & $38.98 \pm 0.59$ \\
\hline HAART use & & $166(\mathrm{n} / \mathrm{N} \%)$ & & 37 & & 129 \\
\hline $\mathrm{CBV}+\mathrm{EFV}$ & - & 69 (41.6) & - & 23 & - & 46 \\
\hline $\mathrm{CBV}+\mathrm{NVP}$ & - & $68(41.0)$ & - & 8 & - & 60 \\
\hline $\mathrm{d} 4 \mathrm{~T}+3 \mathrm{TC}+\mathrm{NVP}$ & - & $18(10.8)$ & - & 1 & - & 17 \\
\hline $\mathrm{d} 4 \mathrm{~T}+3 \mathrm{TC}+\mathrm{EFV}$ & - & $11(6.6)$ & - & 5 & - & 6 \\
\hline
\end{tabular}

Results are presented as means \pm SEM and Proportions of drug use. $* \mathrm{P}<0.05$, $* * \mathrm{P}<0.001$, ***P $<0.0001$ indicates the level of significance when HAART-naïve were compared to those on HAART (unpaired t-test); ${ }^{\dagger} \mathrm{P}<0.05,{ }^{+t} \mathrm{P}<0.001,{ }^{\mathrm{tt}} \mathrm{P}<$ 0.0001 indicates the level of significance when male HAART-naïve were compared to males on HAART; ${ }^{\S} \mathrm{P}<0.05,{ }^{\S} \mathrm{P}<$ $0.001,{ }^{\S \S} \mathrm{P}<0.0001$ indicates the level of significance when female HAART-naïve were compared to females on HAART; ${ }^{\ddagger} \mathrm{P}<0.05,{ }^{*} \mathrm{P}<0.001,{ }^{*} \mathrm{P}<0.0001$ indicates the level of significance when male HAART-naïve were compared to the female HAART-naïve; ${ }^{\mathrm{P}}<0.05,{ }^{\# \prime} \mathrm{P}<0.001,{ }^{\# \#} \mathrm{P}<0.0001$ indicates the level of significance when the male on HAART were compared to the female on HAART. CBV: Combivir, EFV: Efavirenz, NVP: Nevirapine, d4T: Stavudine, 3TC: Lamivudine, HAART: Highly Active Antiretoviral Therapy. 
Estimated GFR's and prevalence of renal insufficiency

Table 2 shows the mean estimated GFR's of the study population as determined with the three estimating equations presented as means \pm SEM. In table 3, the study population was further staged into the five stages of renal function classification system adapted from the National Kidney Foundation (NKF) Kidney Disease Outcome Quality Initiative (K/DOQI) advisory board based on estimated GFR. Chronic decline in GFR (a level of less than $60 \mathrm{~mL} / \mathrm{min} / 1.73 \mathrm{~m}^{2}$ for $>3$ months) is considered as evidence of renal insufficiency although substantial kidney damage can exist without a decrease in GFR. Based on such evidence, the calculated prevalence rates of renal insufficiency (stages 3, 4 and 5) in the study population for Cockcroft-Gault, 4v-MDRD and CKD-EPI equations respectively is $(8.7 \%, 9.1 \%$, $8.7 \%)$ in HAART-naïve patients; $(14.5 \%, 12.6 \%$, $12.6 \%)$ patients on HAART; $(7.7 \%, 11.5 \%, 11.5)$ in HAART-naïve males; $(10.8 \%, 8.1 \%, 8.1 \%)$ in males on HAART; $(9.1 \%, 8.0 \%, 7.5 \%)$ in HAART-naïve females and $(15.5 \%, 14.0 \%, 14.0 \%)$ in females on HAART.

Table 2: Estimated GFR's and mean GFR for the study participants within the GFR stages as determined with the estimating equations

\begin{tabular}{|c|c|c|c|c|c|c|c|}
\hline & & Mean GFR & $\begin{array}{l}\text { Stage 1 } \\
(\geq 90)\end{array}$ & $\begin{array}{l}\text { Stage } 2 \\
(60-89) \\
\end{array}$ & $\begin{array}{r}\text { Stage } 3 \\
(30-59) \\
\end{array}$ & $\begin{array}{c}\text { Stage } 4 \\
(15-29) \\
\end{array}$ & $\begin{array}{l}\text { tage } 5 \\
<15) \\
\end{array}$ \\
\hline \multicolumn{8}{|l|}{ HIV Patients } \\
\hline & CG & $90.59 \pm 14.38$ & $251.00 \pm 41.53$ & $77.05 \pm 1.34$ & $46.69 \pm 2.11$ & $\begin{array}{l}17.48 \pm 1.48 \\
\pm\end{array}$ & $\begin{array}{r}9.73 \\
+5.00\end{array}$ \\
\hline \multirow[t]{3}{*}{$\begin{array}{l}\text { HAART-Naïve } \\
(276)\end{array}$} & 4v-MDRD & $306.50 \pm 39.53$ & $381.20 \pm 49.90$ & $74.71 \pm 1.68$ & $45.73 \pm 2.53$ & $\begin{array}{ll}3 & 22.29 \pm 1.46 \\
\end{array}$ & $\begin{array}{r}6.95 \\
\pm 0.00\end{array}$ \\
\hline & CKD-EPI & $137.20 \pm 4.35$ & $159.20 \pm 4.04$ & $77.46 \pm 1.81$ & $45.09 \pm 1.98$ & $\begin{array}{ll}8 & 20.14 \pm 1.29 \\
\pm\end{array}$ & $\begin{array}{r}9.77 \\
+3.33\end{array}$ \\
\hline & $\mathrm{CG}$ & $93.79 \pm 15.50$ & $269.80 \pm 48.06$ & $76.49 \pm 1.39$ & $43.95 \pm 1.41$ & $0.00 \pm 0.00$ & $\begin{array}{r}0.00 \\
+0.00\end{array}$ \\
\hline \multirow[t]{2}{*}{$\begin{array}{l}\text { On HAART } \\
(166)\end{array}$} & 4v-MDRD & $215.00 \pm 28.45$ & $291.00 \pm 41.03$ & $76.10 \pm 1.51$ & $49.61 \pm 1.38$ & $29.57 \pm 0.00$ & $\begin{array}{r}0.00 \\
\pm 0.00\end{array}$ \\
\hline & CKD-EPI & $120.00 \pm 4.36$ & $145.10 \pm 4.51$ & $75.34 \pm 1.39$ & $50.06 \pm 1.38$ & $28.61 \pm 0.00$ & $\begin{array}{r}0.00 \\
+0.00\end{array}$ \\
\hline \multicolumn{8}{|l|}{ Male patients } \\
\hline & $\mathrm{CG}$ & $85.68 \pm 18.98$ & $216.90 \pm 44.37$ & $70.91 \pm 3.24$ & $53.89 \pm 0.26$ & $\begin{array}{rr}6 & 24.23 \pm 3.09 \\
\pm\end{array}$ & $\begin{array}{r}0.00 \\
\pm 0.00\end{array}$ \\
\hline \multirow[t]{3}{*}{ HAART-Naïve (78) } & $4 \mathrm{v}-\mathrm{MDRD}$ & $249.90 \pm 37.45$ & $306.00 \pm 45.07$ & $82.69 \pm 2.57$ & $43.27 \pm 3.51$ & $\begin{array}{r}125.61 \pm 2.26 \\
\pm\end{array}$ & $\begin{array}{r}0.00 \\
\pm 0.00\end{array}$ \\
\hline & CKD-EPI & $136.60 \pm 8.29$ & $160.50 \pm 7.53$ & $83.31 \pm 2.65$ & $44.63 \pm 3.04$ & $\begin{array}{r}424.61 \pm 1.84 \\
\pm\end{array}$ & $\begin{array}{r}0.00 \\
+0.00\end{array}$ \\
\hline & $\mathrm{CG}$ & $102.10 \pm 41.32$ & $371.9 \pm 163.40$ & $78.40 \pm 3.12$ & $43.90 \pm 5.16$ & $\begin{array}{ll}6 & 0.00 \pm 0.00 \\
\end{array}$ & $\begin{array}{r}0.00 \\
\pm 0.00\end{array}$ \\
\hline \multirow[t]{2}{*}{ On HAART (37) } & 4v-MDRD & $221.50 \pm 66.99$ & $303.2 \pm 99.99$ & $77.56 \pm 2.32$ & $57.48 \pm 0.39$ & $\begin{array}{rr}39 & 29.57 \pm 0.00 \\
\pm\end{array}$ & $\begin{array}{r}0.00 \\
\pm 0.00\end{array}$ \\
\hline & CKD-EPI & $120.20 \pm 9.64$ & $145.0 \pm 11.08$ & $75.58 \pm 2.04$ & $57.22 \pm 0.30$ & $\begin{array}{rr}0 & 28.61 \pm 0.00 \\
\pm\end{array}$ & $\begin{array}{r}0.00 \\
\pm 0.00\end{array}$ \\
\hline \multicolumn{8}{|l|}{ Female patients } \\
\hline & $\mathrm{CG}$ & $97.30 \pm 15.07$ & $253.20 \pm 40.31$ & $75.66 \pm 1.37$ & $44.63 \pm 2.75$ & $\begin{array}{r}518.81 \pm 2.66 \\
\pm\end{array}$ & $\begin{array}{r}9.73 \\
+5.01\end{array}$ \\
\hline \multirow[t]{3}{*}{ HAART-Naïve (198) } & 4v-MDRD & $332.30 \pm 45.67$ & $393.40 \pm 54.56$ & $75.68 \pm 1.94$ & $46.88 \pm 3.35$ & $\begin{array}{rr}5 & 19.40 \pm 1.60 \\
\pm\end{array}$ & $\begin{array}{r}6.95 \\
+0.00\end{array}$ \\
\hline & CKD-EPI & $143.00 \pm 4.56$ & $160.20 \pm 4.22$ & $77.35 \pm 2.05$ & $47.01 \pm 3.74$ & $\begin{array}{rr}4 & 19.75 \pm 0.92 \\
\pm\end{array}$ & $\begin{array}{r}8.05 \\
+0.00\end{array}$ \\
\hline & CG & $90.47 \pm 15.77$ & $245.80 \pm 46.05$ & $75.79 \pm 1.55$ & $42.13 \pm 1.21$ & $\begin{array}{r}0.00 \pm 0.00 \\
\pm(\end{array}$ & $\begin{array}{r}0.00 \\
=0.00\end{array}$ \\
\hline \multirow[t]{2}{*}{ On HAART (129) } & 4v-MDRD & $202.20 \pm 29.96$ & $273.30 \pm 43.27$ & $75.47 \pm 1.94$ & $48.37 \pm 1.33$ & $\begin{array}{l}0.00 \pm 0.00 \\
\pm 0\end{array}$ & $\begin{array}{r}0.00 \\
=0.00\end{array}$ \\
\hline & CKD-EPI & $117.80 \pm 4.75$ & $143.00 \pm 4.711$ & $75.24 \pm 1.83$ & $48.91 \pm 1.37$ & $\begin{array}{r}0.00 \pm 0.00 \\
\pm 0\end{array}$ & $\begin{array}{r}0.00 \\
\quad 0.00 \\
\end{array}$ \\
\hline
\end{tabular}

Results are presented as Mean \pm SEM. CG: Cockcroft - Gault, 4v-MDRD: Four-variable Modification of Diet in Renal Disease, CKD-EQI: Chronic Kidney Disease Epidemiology Collaboration (CKD-EPI) Equation, HAART: Highly active antiretroviral therapy, GFR: Glomerular filtration rate. 
Table 3: Prevalence of renal insufficiency and distribution of study participants into the different stages of GFR

\begin{tabular}{|c|c|c|c|c|c|c|c|}
\hline & eGFR Equa & $\begin{array}{c}\text { ns Stage } 1 \\
(>=90)\end{array}$ & $\begin{array}{r}\text { Stage } 2 \\
(60-89)\end{array}$ & $\begin{array}{r}\text { Stage } 3 \\
(30-59)\end{array}$ & $\begin{array}{l}\text { Stage } 4 \\
(15-29)\end{array}$ & $\begin{array}{l}\text { Stage } 5 \\
(<15)\end{array}$ & $\begin{array}{l}\text { Renal } \\
\text { insufficiency }(\%)\end{array}$ \\
\hline \multicolumn{8}{|l|}{ HIV patients } \\
\hline & CG & $209(75.7)$ & $43(15.6)$ & $13(4.7)$ & $9(3.3)$ & $2(0.7)$ & $24(8.7)$ \\
\hline \multirow{3}{*}{$\begin{array}{l}\text { HAART-Naïve } \\
\text { (276) }\end{array}$} & 4v-MDRD & $227(82.2)$ & $24(8.7)$ & $13(4.7)$ & $11(4.0)$ & $1(0.4)$ & $25(9.1)$ \\
\hline & CKD-EPI & $230(83.3)$ & $22(8.0)$ & $12(4.3)$ & $11(4.0)$ & $1(0.4)$ & $24(8.7)$ \\
\hline & CG & $111(66.9)$ & 31(18.7) & $24(14.5)$ & $0(0.0)$ & $0(0.0)$ & $24(14.5)$ \\
\hline \multirow[t]{2}{*}{ On HAART (166) } & 4v-MDRD & $112(67.5)$ & $33(19.9)$ & $20(12.0)$ & $1(0.6)$ & $0(0.0)$ & 21(12.6) \\
\hline & CKD-EPI & 116(69.9) & $29(17.5)$ & $20(12.0)$ & $1(0.6)$ & $0(0.0)$ & 21(12.6) \\
\hline \multicolumn{8}{|l|}{ Male patients } \\
\hline & CG & 63(80.8) & $9(11.5)$ & 2(2.6) & $4(5.1)$ & $0(0.0)$ & $6(7.7)$ \\
\hline \multirow[t]{3}{*}{ HAART-Naïve (78) } & 4v-MDRD & $64(82.1)$ & $5(6.4)$ & $6(7.7)$ & $3(3.8)$ & $0(0.0)$ & $9(11.5)$ \\
\hline & CKD-EPI & $64(82.1)$ & $5(6.4)$ & $5(6.4)$ & $4(5.1)$ & $0(0.0)$ & $9(11.5)$ \\
\hline & CG & $25(67.6)$ & $8(21.6)$ & $4(10.8)$ & $0(0.0)$ & $0(0.0)$ & $4(10.8)$ \\
\hline \multirow[t]{2}{*}{ On HAART (37) } & 4v-MDRD & $24(64.9)$ & $10(27.0)$ & $2(5.4)$ & $1(2.7)$ & $0(0.0)$ & $3(8.1)$ \\
\hline & CKD-EPI & $25(67.6)$ & $9(24.3)$ & 2(5.4) & $1(2.7)$ & $0(0.0)$ & $3(8.1)$ \\
\hline \multicolumn{8}{|l|}{ Female patients } \\
\hline & CG & $146(73.7)$ & $34(17.2)$ & $11(5.6)$ & $5(2.5)$ & $2(1.0)$ & $18(9.1)$ \\
\hline \multirow{3}{*}{$\begin{array}{l}\text { HAART-Naïve } \\
\text { (198) }\end{array}$} & 4v-MDRD & $163(82.3)$ & 19(9.6) & $7(3.5)$ & $8(4.0)$ & $1(0.5)$ & $16(8.0)$ \\
\hline & CKD-EPI & $166(83.8)$ & $17(8.6)$ & $7(3.5)$ & $7(3.5)$ & $1(0.5)$ & $15(7.5)$ \\
\hline & CG & $86(66.7)$ & $23(17.8)$ & $20(15.5)$ & $0(0.0)$ & $0(0.0)$ & $20(15.5)$ \\
\hline \multirow[t]{2}{*}{ On HAART (129) } & 4v-MDRD & $88(68.2)$ & $23(17.8)$ & $18(14.0)$ & $0(0.0)$ & $0(0.0)$ & $18(14.0)$ \\
\hline & CKD-EPI & $91(70.5)$ & $20(15.5)$ & $18(14.0)$ & $0(0.0)$ & $0(0.0)$ & $18(14.0)$ \\
\hline
\end{tabular}

eGFR = Estimated Glomerular Filtration Rate, CG = Cockcroft-Gault, 4v-MDRD = 4-variable Modification of Diet in Renal Disease, $\mathrm{CKD}$-EPI = Chronic Kidney Disease Epidemiology Collaboration

\section{Study parameters as predictor variables}

Table 4 shows summarized beta (â) and "r squared $\left(\mathrm{r}^{2}\right)$ " values of multiple linear regression analysis of some study parameters with the exception of CD4 for which variability changes are known to have varied effects on serum creatinine concentration and estimated GFR with the three renal function equations. Serum creatinine showed a consistent reciprocal relationship to estimated GFR with $\mathrm{r}^{2}$ values observed in CKD-EPI equation $>4 \mathrm{v}$-MDRD $>$ Cockcroft-Gault equations respectively in all the study populations. CD4 was the next predictor variable which showed a consistent positive relationship with estimated GFR. Generally, $\mathrm{r}^{2}$ values in the CockcroftGault equation $>4 \mathrm{v}$-MDRD $>$ CKD-EPI equations respectively with exceptions in HIV patients on HAART $\left(\mathrm{r}^{2}\right.$ in $\left.4 \mathrm{v}-\mathrm{MDRD}=\mathrm{CKD}-\mathrm{EPI}\right)$; HAARTnaïve males ( $\mathrm{r}^{2}$ in CKD-EPI $>4 \mathrm{v}$-MDRD) and females on HAART ( $\mathrm{r}^{2}$ in Cockcroft-Gault and $4 \mathrm{v}-$ MDRD $=0 \%$; CKD-EPI $=1 \%$ ). Weight was the next predictor in succession and it also showed a positive relationship to GFR with the exception of observed negative associations in the $4 \mathrm{v}-\mathrm{MDRD}$ and CKD-EPI equations for females on HAART. Strong $\mathrm{r}^{2}$ values were observed in the Cockcroft-
Gault equation compared to the 4v-MDRD and CKD-EPI equations with an exception in females on HAART where the $r^{2}$ in Cockcroft-Gault $=0 \%$ and $1 \%$ in $4 \mathrm{v}-\mathrm{MDRD}$ and CKD-EPI equations respectively. Age was the next in succession showing a generally negative or reciprocal relationship to estimated GFR with exceptions of positive associations in males on HAART and estimated GFR by Cockcroft-Gault in HAART-naïve males. There was no consistency in the $r^{2}$ values calculated for the three equations in all the study populations. Serum albumin concentration was the last predictor in succession and it showed reciprocal relationship in the HAART naive study population (naïve males and females) and positive linear relationship in the subject population on HAART (males and females on HAART). Again, there was no consistency in the calculated $\mathrm{r}^{2}$ values for all the study populations.

Therefore in grading the predictor variables with regard to strength of association and percentage variability with estimated GFR in the study population, the outcome is creatinine $>\mathrm{CD} 4>$ weight $>$ age $>$ albumin. 
Table 4: Beta and " $r$ " squared $\left(\mathrm{r}^{2}\right)$ values from linear regression analysis of some study parameters against the estimating equations

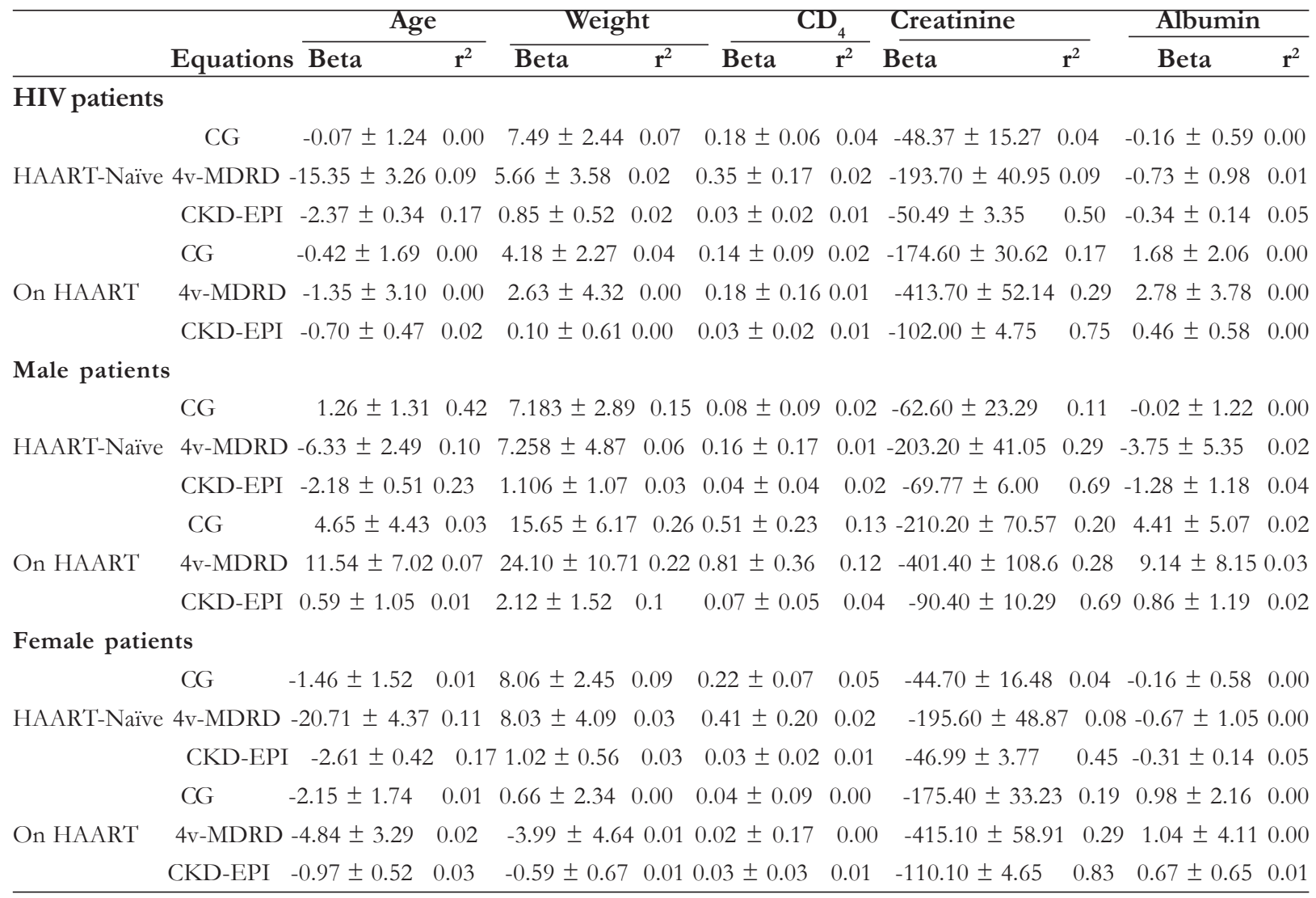

\section{Comparison of methods (Bland-Altman}

\section{analysis)}

Graphical comparisons of the performance of the three estimating equations were assessed by the Bland-Altman method of comparison where the difference between measurements of the estimating equations is plotted as a function of the average of the two measurements. Bias was assessed as the mean difference, with positive values indicating an underestimation of GFR. Limits of agreement were computed as the mean bias plus or minus 1.96 times its standard deviation (SD).

In figures 1, 2 and $3, A$ and $A_{1}$ show comparison between $4 \mathrm{v}-\mathrm{MDRD}$ equation and the Cockcroft-Gault equation while $\mathrm{B}$ and $\mathrm{B}_{1}$ show comparison between $4 \mathrm{v}-\mathrm{MDRD}$ and the CKD-EPI equation and $\mathrm{C}$ and $\mathrm{C}_{1}$ show comparison between CKD-EPI and the Cockcroft-Gault equation. From figures 1, 2 and 3, the 4v-MDRD vs CKD-EPI comparison consistently yielded lower bias than the CKD-EPI vs Cockcroft-Gault comparison which also gave a lower bias in relation to the $4 \mathrm{v}$-MDRD vs Cockcrof-Gault comparison. Observed differences in estimated GFR were due to proportional errors or variations in the magnitude of measurements attributed to the variable composition and formulation of the estimating equations. 

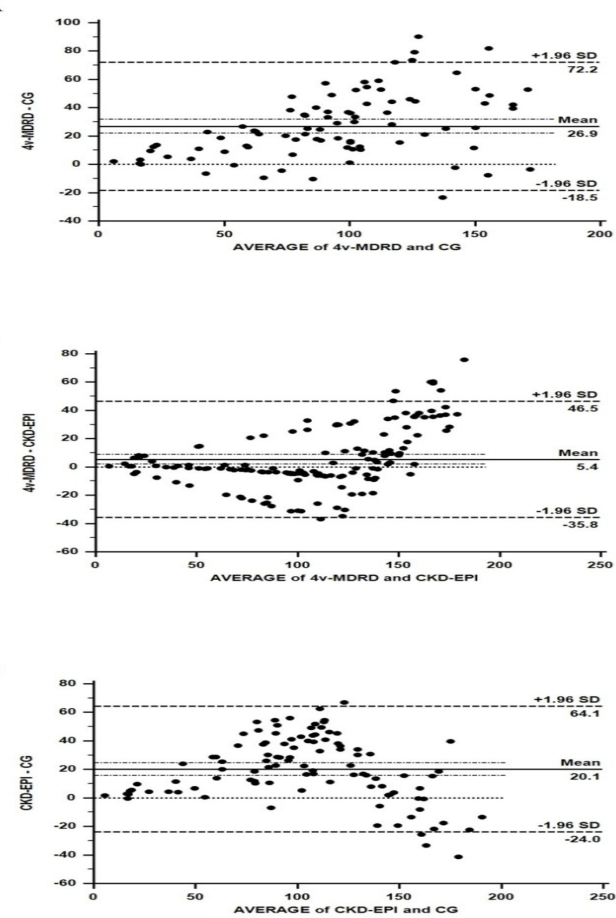

A 1

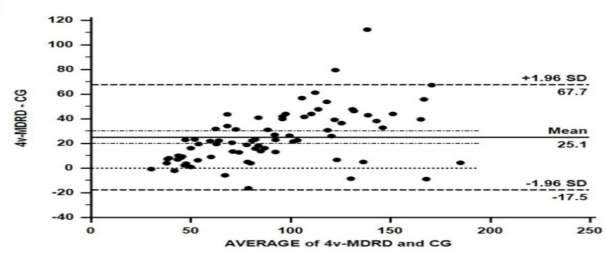

B1

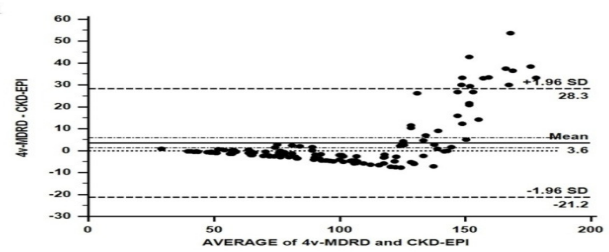

C

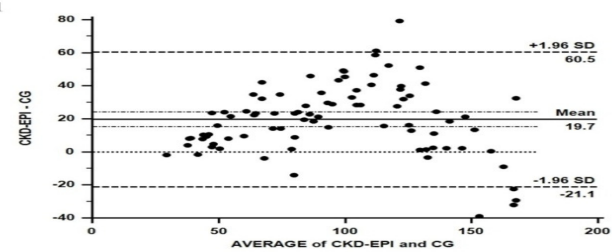

Figure 1: Bland-Altman comparison of the estimating equations in HAART-naïve patients (A, B \& C) and those on HAART $\left(A_{1}, B_{1} \& C_{1}\right)$
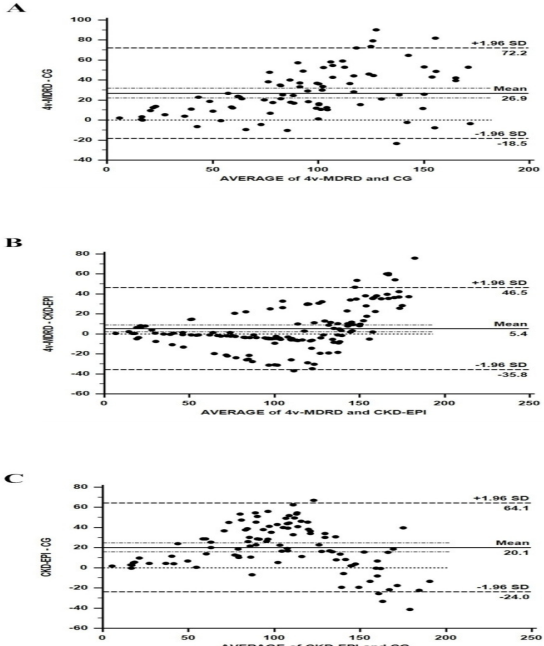

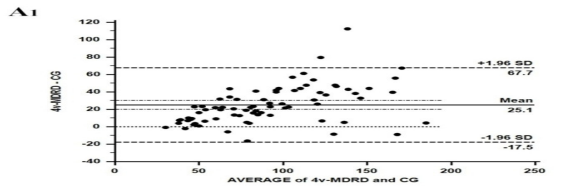

B.
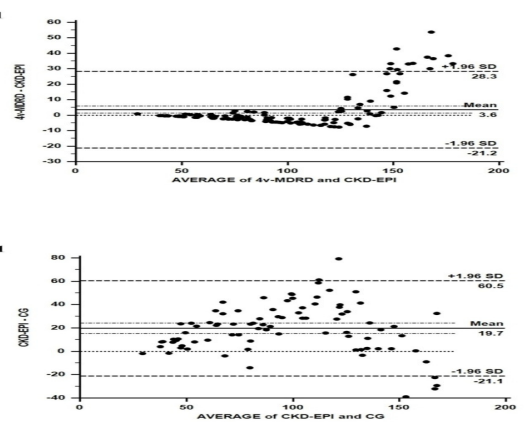

Figure 2: Bland-Altman comparison of the estimating equations in HAART-naive male patients (A, B \& C) and those on (HAART $\left(A_{1}, B_{1} \& C_{1}\right)$
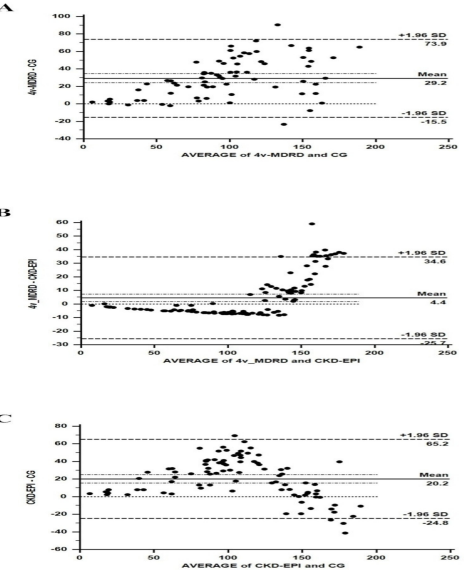

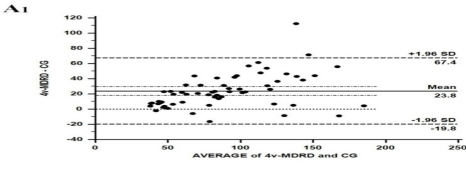

B.
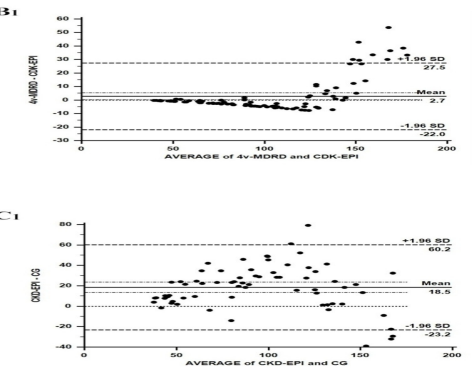

Figure 3: Bland-Altman comparison of the estimating equations in HAART-naïve female patients $(A, B \& C)$ and those $\operatorname{HAART}\left(\mathrm{A}_{1}, \mathrm{~B}_{1} \& \mathrm{C}_{1}\right)$ 


\section{Discussion}

Prevalence of renal insufficiency

The Infectious Diseases Society of America (IDSA) recommends the simplified MDRD equation for staging renal disease and the Cockcroft-Gault equation for dosage modification ${ }^{11}$. The calculated incidence of renal insufficiency (GFR $<60 \mathrm{~mL} / \mathrm{min}$ / $1.73 \mathrm{~m}^{2}$; stages $3,4 \& 5$ ) in male and female patients (HAART-naïve + on HAART) was $9.8 \%$ and $11.1 \%$ respectively giving an overall average incidence of $10.5 \%$ using the $4 \mathrm{v}-\mathrm{MDRD}$ equation ${ }^{21}$ reported a renal insufficiency $(\mathrm{CrCl}<60 \mathrm{~mL} / \mathrm{min}$ and $<50 \mathrm{~mL} /$ min) incidence of $11.5 \%$ and $4.8 \%$ respectively in a cross-sectional study in an antiretroviral (ARV) naïve Kenyan population. This significant finding suggests that renal insufficiency is a growing health concern in our study population and it is certainly underdiagnosed and under-treated considering the fact that apart from results of full serum chemistries, none of the study participants had a documented creatinine clearance on which antiretroviral (ART) dosing was based. The provision of absolute creatinine values rather than calculated creatinine clearance values by most laboratories for patients is not in keeping with recommended guidelines of the IDSA which recommends that therapy should be dependent on level of creatinine clearance. Renal insufficiency in this study as estimated by the Cockcroft-Gault equation in male and female (on HAART + HAART-naïve) patients was $8.4 \%$ and $13.2 \%$ respectively giving an overall average of $10.8 \%$. A significant proportion of our study population may therefore have required dosage adjustment at the time of initiation of therapy or sometime during on-going therapy.

\section{Dose adjustment}

The Infectious Diseases Society of America ART dosing recommendations suggests that appropriate reduction of dosing for ART's that are primarily eliminated by the kidneys is warranted. Dose adjustments for NNRTI's in patients with renal insufficiency is not required because NNRTI's in general are much more tightly bound to plasma proteins and are primarily metabolized by the liver ${ }^{11}$ - They also have high molecular weights and are excreted into the urine in low amounts. Nevirapine, however, does not fully share the drug properties of the other NNRTI's because of its relatively low molecular weight and protein-binding fraction ${ }^{11}$. It has therefore been suggested that dialysis may remove substantial amounts of the drug and that it should be administered after dialysis. Nucleoside reverse transcriptase inhibitors on the other hand are primarily excreted by the kidneys, therefore reduced dosage is required in patients with impaired renal function, especially for a drug like stavudine, which requires further reduction because its pharmacokinetics is influenced by weight ${ }^{11}$. Furthermore, because NRTI's are neither tightly bound to protein nor have a high molecular weight, they may be easily removed by dialysis. The drug regimen for the study population includes the standard combination therapy of 2 NRTI's and 1 NNRTI. The NRTI's include stavudine (d4T), lamivudine (3TC) and combivir (combined drug of Zidovudine (AZT) + 3TC) and the NNRTI's includes efavirenz (EFV) and Nevirapine (NVP). The study population on $\mathrm{d} 4 \mathrm{~T}$ and $3 \mathrm{TC}$ who present with renal insufficiency will require dose adjustments as per the IDSA recommendations with combivir being administered as separate component medications in patients with creatinine clearance $<50 \mathrm{~mL} / \mathrm{min}$.

\section{Method comparison}

A comparison of the performance of the equations in estimating GFR in the study population showed the $4 \mathrm{v}$-MDRD vs CKD-EPI comparison giving consistently lower bias than the CKD-EPI vs Cockcroft-Gault comparison which also gave a lower bias in relation to the $4 \mathrm{v}-\mathrm{MDRD}$ vs CockcroftGault comparison. The lower bias observed in the $4 \mathrm{v}-\mathrm{MDRD}$ vs CKD-EPI should reduce the rate of false-positive diagnoses of stage 3 renal insufficiency (estimated GFR $<60 \mathrm{~mL} / \mathrm{min} / 1.73 \mathrm{~m}^{2}$ ) in patients without renal insufficiency and no markers of kidney damage. The ability of the CKD-EPI equation to compare well with the $4 \mathrm{v}-\mathrm{MDRD}$ equation, the recommended equation for staging $\mathrm{CKD}^{11}$, simply means that the CKD-EPI equation although not validated in our study population could be used interchangeably with the 4v-MDRD equation for effective staging of renal insufficiency in $\mathrm{HIV}$-infected patients. Cockcroft-Gault equation on the other hand underestimates GFR compared to the $4 \mathrm{v}$-MDRD and CKD-EPI equations and could lead to falsely low GFR's which could lead to insufficient drug dosing in patients without renal insufficiency. This observation is in agreement with our previous finding among CKD patients ${ }^{20}$. 


\section{Study predictors}

In the linear regression model to assess the ability of creatinine, weight, age, CD4 and albumin to predict GFR in all the estimating equations, creatinine and age showed reciprocal relationship to GFR. Endogenous creatinine is solely excreted by the kidneys and a fractional reduction in urine creatinine excretion will lead to an increase in serum concentrations of creatinine hence reduced GFR being associated with high serum creatinine concentration. Older age is an independent predictor of lower GFR and mainly reflects the relationship between age and muscle mass ${ }^{22}$. Lower muscle mass in older persons causes lower urine creatinine excretion because of the lower serum creatinine concentration hence the negative relationship. Weight and CD4 gave positive linear relationship with GFR estimated with the equations. Increase in body weight is associated with increase in muscle mass with proportional increase in creatinine production which is excreted with a fractional increase in GFR. Cockcroft-Gault equation incorporates creatinine (inverse relationship), weight (direct relationship) and age (natural scale) in estimating GFR whilst CKDEPI incorporates log serum creatinine (modeled as a 2-slope linear spline with sex specific knots at $0.7 \mathrm{mg} / \mathrm{dL}$ for women and $0.9 \mathrm{mg} / \mathrm{dL}$ in men) and age (on a natural scale) ${ }^{23}$ and $4 \mathrm{v}$-MDRD incorporates log serum creatinine (without a spline) and age (on $\log$ scale $)^{23}$. The composition and variables in the estimating equations may explain some of the differences in their ability to estimate GFR. Weight was an independent predictor of estimated GFR in the Cockcroft-Gault equation than in the 4v-MDRD and CKD-EPI equations and this could be attributed to weight in a direct relationship to GFR in the Cockcroft-Gault equation compared to the latter equations which have been adjusted for body surface area. Serum creatinine is a strong predictor of GFR in the CKD-EPI equation and CD4 which is not included in any of the estimating equations was a strong predictor of GFR in the Cockcroft-Gault equation. The Cockcroft-Gault equation, which is recommended for dose modification, may therefore serve as an invaluable tool in the HIV-infected population if an adjustment could be made for the inclusion of CD4 results. The association of serum creatinine and the CKD-EPI equation may give an added reason why the CKD-EPI equation would be a better tool in staging renal insufficiency in HIVinfected patients ${ }^{24}$. reported a CKD prevalence of about $50 \%$ in the elderly population and the significant finding of increases in age and weight in patients on HAART and females on HAART compared to their HAART-naïve counterparts calls for a critical assessment of GFR in this study group for effective dosage adjustment in the presence of renal insufficiency.

\section{Conclusion}

Results from this study provides evidence of the presence of renal insufficiency in HIV-infected patients in Ghana, a significant proportion of who will require dose adjustment at the time of initiation of therapy or sometime during ongoing therapy (as realized with patients on HAART in this study). The CKD-EPI equation could serve as the best equation for staging of renal insufficiency in this study population considering its low bias in comparison to the $4 \mathrm{v}-\mathrm{MDRD}$ equation and its strong association with serum creatinine concentration.

\section{Study limitations}

1. The study's inability to estimate creatinine clearance (gold standard) for each of the participating patients was a major limitation which made it virtually impossible to assess how the estimating equations compare to the gold standard. Caution should therefore be exercised in adopting any of the estimating equations in this study cohort.

2. The study is unable to confidently distinguish between patients with acute renal insufficiency from those with chronic kidney disease.

3. Factors such as diet, protein intake and muscle wasting can and may have had profound effect on estimated GFR's.

4. The study did not attempt to determine the causes of renal insufficiency among the participants.

5. The estimating equations do not overcome the limitations of serum creatinine as an endogenous filtration marker and as such all creatinine-based equations should be used with caution in people with abnormally high or low muscle mass.

\section{References}

1. Coresh J, Astor BC, Greene T, Eknoyan G, Levey AS. Prevalence of chronic kidney disease and decreased kidney function in the adult US population: Third National Health and Nutrition Examination Survey. Am J Kidney Dis 2003; 41(1):1-12. 
2. Obrador GT, Ruthazer R, Arora P, Kausz AT, Pereira BJ. Prevalence of and factors associated with suboptimal care before initiation of dialysis in the United States. I Am Soc Nephrol 1999; 10(8):1793-1800.

3. Nissenson AR, Collins AJ, Hurley J, Petersen H, Pereira BJ, Steinberg EP. Opportunities for improving the care of patients with chronic renal insufficiency: current practice patterns. J Am Soc Nephrol 2001; 12(8):1713-1720.

4. Szczech LA, Gange SJ, van der Horst C, Bartlett JA, Young M, Cohen MH, Anastos K, et al. Predictors of proteinuria and renal failure among women with HIV infection. Kidney Int 2002; 61(1):195-202.

5. Wyatt CM, Winston JA, Malvestutto CD, Fishbein DA, Barash I, Cohen AJ, Klotman ME, Klotman PE. Chronic kidney disease in HIV infection: an urban epidemic. AIDS 2007; 21(15):2101-2103.

6. Laradi A, Mallet A, Beaufils H, Allouache M, Martinez F. HIV-associated nephropathy: outcome and prognosis factors. Groupe d' Etudes Nephrologiques d'Ile de France. J Am Soc Nephrol 1998; 9(12):2327-2335.

7. Kimmel PL, Barisoni L, Kopp JB. Pathogenesis and treatment of HIV-associated renal diseases: lessons from clinical and animal studies, molecular pathologic correlations, and genetic investigations. Ann Intern Med 2003; 139(3):214-226.

8. Gerntholtz TE, Goetsch SJ, Katz I. HIV-related nephropathy: a South African perspective. Kidney Int 2006, 69(10):1885-1891.

9. Kalayjian RC, Franceschini N, Gupta SK, Szczech LA, Mupere E, Bosch RJ, Set al. Suppression of HIV-1 replication by antiretroviral therapy improves renal function in persons with low CD4 cell counts and chronic kidney disease. AIDS 2008; 22(4):481-487.

10. Palella FJ, Delaney, K.M, Moorman, A.C, et al. Declining Morbidity and Mortality among Patients with Advanced Human Immunodeficiency Virus Infection. New England Journal of Medicine 1999; 279:853-860.

11. Gupta SK, Eustace JA, Winston JA, Boydstun, II, Ahuja TS, Rodriguez RA, Tashima KT, et al: Guidelines for the management of chronic kidney disease in HIV-infected patients: recommendations of the HIV Medicine Association of the Infectious Diseases Society of America. Clin Infect Dis 2005; 40(11):1559-1585.

12. National Kidney Foundation.K/DOQI clinical practice guidelines for chronic kidney disease: evaluation, classification, and stratification. Am J Kidney Dis 2002; 39(2 Suppl 1):S1-266.
13. Stevens LA, Coresh J, Greene T, Levey AS: Assessing kidney function-measured and estimated glomerular filtration rate. $N$ Engl J Med 2006; 354(23):2473-2483.

14. Cockcroft DW, Gault MH. Prediction of creatinine clearance from serum creatinine. Nephron 1976; 16(1):31-41.

15. Levey AS, Bosch JP, Lewis JB, Greene T, Rogers N, Roth D: A more accurate method to estimate glomerular filtration rate from serum creatinine: a new prediction equation. Modification of Diet in Renal Disease Study Group. Ann Intern Med 1999, 130(6):461-470.

16. Winston J, Deray G, Hawkins T, Szczech L, Wyatt C, Young B. Kidney disease in patients with HIV infection and AIDS. Clin Infect Dis 2008, 47(11):1449-1457.

17. Talke H, Schubert GE. Enzymatic Urea Determination in the Blood and Serum in the Warburg Optical Test. Klin Wochenschr 1965, 43:174-175.

18. Fabiny DL, Ertingshausen G: Automated reaction-rate method for determination of serum creatinine with the CentrifiChem. Clin Chem 1971; 17(8):696-700.

19. Doumas BT, Watson WA, Biggs HG: Albumin standards and the measurement of serum albumin with bromcresol green. Clin Chim Acta 1971; 31(1):87-96.

20. Owiredu WKBA, Ephraim RKD, Amidu N, Eghan BAJ, Quaye L: Predictive performance of renal function equations among ghanaians presenting with chronic kidney disease. $J$ Medical Sci 2008; 8:491-497.

21. Wools-Kaloustian K, Gupta SK, Muloma E, Owino-Ong'or W, Sidle J, Aubrey RW, Shen J, et al. Renal disease in an antiretroviral-naive HIVinfected outpatient population in Western Kenya. Nephrol Dial Transplant 2007; 22(8):2208-2212.

22. Heymsfield SB, Arteaga C, McManus C, Smith J, Moffitt S: Measurement of muscle mass in humans: validity of the 24-hour urinary creatinine method. Am J Clin Nutr 1983; 37(3):478-494.

23. Levey AS, Stevens LA, Schmid CH, Zhang YL, Castro AF, 3rd, Feldman HI, Kusek JW, et al: A new equation to estimate glomerular filtration rate. Ann Intern Med 2009; 150(9):604-612.

24. Coresh J, Selvin E, Stevens LA, Manzi J, Kusek JW, Eggers P, et al. Prevalence of chronic kidney disease in the United States. JAMA 2007; 298(17):2038-2047. 